\title{
Mathematical website constructions for prospective elementary school teachers
}

\author{
Jack Carter and Beverly J. Ferrucci \\ California State University, Hayward CA 94542-3092 USA. jcarter@csuhayward.edu \\ Keene State College, Keene NH USA
}

Keywords: pre-service teacher education, mathematics education, websites

\begin{abstract}
This study explored the performance of pre-service elementary school mathematics teachers who created, modified, and uploaded web pages for a future classroom site. Results showed the prospective teachers were successful: (1) using a web page editor, images, and links to prepare their individual website projects; and (2) completing examination items related to website construction. More than $70 \%$ of the future teachers indicated they enjoyed the project, and an equal percentage reported they had learned web page editing skills. Suggestions for enhancing the changed curriculum included increasing the emphasis on mathematics learning and better integrating content on spreadsheets and websites.
\end{abstract}

\section{BACKGROUND}

Recent research reports have directed attention to important considerations in using the World Wide Web (WWW) for instructional purposes generally and in designing and implementing website projects for pre-service teachers particularly. Shotsberger (1996) surveyed existing efforts at using the WWW for instructional purposes, pointed out innovative uses of the web, and suggested ways instructors could optimise the design of instructional sites. Since most of the instructional sites that were surveyed functioned as adjuncts to the classroom, Shotsberger found that such sites were mainly archival in nature and their primary purpose was to reinforce instruction. Moreover, three considerations appeared to constitute good WWW document design: (1) more and shorter web pages having few links were generally better than a small number of long pages with many links;

The original version of this chapter was revised: The copyright line was incorrect. This has been corrected. The Erratum to this chapter is available at DOI: 10.1007/978-0-387-35499-6_29 
(2) pages that included options to enhance navigability, and paragraphs and lists that had common formats were exemplars of consistency in website design; and (3) winnowing a site of inappropriate, extraneous, or redundant material was necessary to ensure the site did not become rich in visual enhancements but devoid of real content. Finally, Shotsberger noted that student work, the centrepiece of any course, was prominently displayed in better instructional sites.

The recent literature has also emphasised the WWW as an important platform for pre-service teacher education. Halpin and Kossegi (1996) included WWW searches in courses for prospective teachers and measured their attitudes on the use of the web with a questionnaire. The results indicated that the students believed that web technology was apt to be a major and positive influence in their future teaching.

Mathematics teacher education on the WWW was the focus of Jiang and McClintock's 1997 research report on how future teachers used web resources to organise, analyse and share data. Particularly, the authors noted that the pre-service teachers recognised that using web resources was an effective way to learn mathematics. Also noteworthy was the fact that students in the study sent solutions or comments to the sites they had explored, and thus became experienced at sharing ideas with people across cities, regions and countries. The authors noted that their research subjects expressed the need to create their own web pages and recognised the value of term projects and electronic forums to answer questions or seek support when learning difficulties arose. These findings were reiterated by Charland (1998) in a recent article for practising teachers on classroom homepages.

Gerber, Shuell, and Harlos (1998) explored how the Internet might be used in a classroom mathematics project and investigated how students learned in this instructional environment. Results showed that the students mainly regarded the web as a source of information and a means to communicate with others.

\section{PROCEDURES}

Based on the preceding reports there is ample support for website assignments for prospective elementary school mathematics teachers and for a WWW project as part of a mathematics content course for these future teachers. The preceding studies also point out that students regard the web primarily as a valuable source of information and a means for communication. Consequently, a reasonable focus for a project for the future teachers could be a review of mathematical content commonly encountered in elementary school programmes. Along with this mathematical review, the authors made the decision to incorporate web 
pages within the assigned project to illustrate and emphasise the importance of both Internet and content skills. The authors further decided to make topics in descriptive statistics the focus of the content in the websites that the pre-service teachers created. This content selection was particularly motivated by the fact that descriptive statistics constitute a major portion of the initial half of the content course into which the web project was to be incorporated.

Since the study by Jiang and McClintock (1997) found that pre-service teachers see the need for experience in creating web pages, it was also decided to make the construction of web pages a main emphasis of the prospective teachers' project. Following the guidelines established by Shotsberger (1996), it was further determined that the project would provide exemplars of good website design within an easily navigable website. Also, following the examples provided by the preceding research reports, the decision was made to document this curricular change by conducting an exploratory study of the resultant student performance outcomes. Thus, the purpose of this study was to explore pre-service elementary school teachers' performance in a mathematics content course as they used the WWW and website software to create, modify and upload web pages for their individual, future classroom sites.

The website activities for the study consisted of three 110-minute computer sessions using software to construct, modify and upload websites. Following the computer sessions students completed a website project and then an exam on the website software they had used. After the exam the prospective teachers completed a questionnaire about the project.

The activities for the study spanned two weeks with the computer sessions on days 1,6 , and 8 , and the exam and questionnaire administered on day 13. website projects were also completed by day 13 .

Prior to the first session at the computer, students received details of the website project along with a sheet of information about URLs, account numbers and passwords. The project required the future teachers to customise a website that contained class information along with a statistical review for the prospective teachers' future students. After customising the website, the students also needed to upload the site.

An individual folder of each student's partially completed website was prepared on a diskette and an electronic discussion forum was established for the class members and instructor to use in facilitating communication and networking. This communication and networking component enabled the participants to discuss questions about the project, to solve problems that arose, to give advice on URLs and other web-related resources, and to check on the overall progress of the project. 
During the computer sessions the pre-service teachers received instruction about the website software and completed activities using the software and the Internet. The first computer session focused on locating background graphics and mathematical title graphics on the Internet, saving images, and creating a table within a web page to display and describe images. The second computer session was devoted to the topics of modifying text and backgrounds, uploading modified websites, and making links to pages within a website. The third class session emphasised searching for and saving graphic images, inserting images into web pages, and creating links to the Internet. During the third computer session students were also reminded of the need to consider both grouped and un-grouped data in reviewing statistical measures of centrality and dispersion.

The pre-service teachers were afforded an opportunity to communicate and network with each other via their websites' internal electronic discussion forum. Also, the students' websites contained pages for classroom information and pages on which each prospective teacher was to prepare a review of elementary concepts from descriptive statistics.

The website projects were scored on a scale from 0 to 150 with 50 points being the maximum possible score for completing the web page(s) that reviewed each of the three statistical concepts of mean, median, and interquartile range.

The exam on the website software included questions on the edit, preview, and source modes for viewing and modifying web pages. Other questions related to the use of dialogue boxes and pop-up menus that students used to insert background graphics and to change font colours for text and links within web pages. Still other questions on the exam dealt with website files and with the creation and use of links in websites.

After completing the exam the prospective teachers were asked to complete a questionnaire about the website project. Particular questions asked whether they liked the project, what they learned from doing the project, and why they selected the material they used in preparing their web pages. A final question asked the future teachers whether the project helped them to see classroom applications for websites and to give examples of such applications.

\section{RESULTS}

Twenty-one of the prospective elementary school teachers completed the website project. In all, the project accounted for approximately $8 \%$ of the students' grade in the course and the students' average score was approximately $87.3 \%$. Scores on the project ranged from $66.7 \%$ to $100 \%$. 
Table 1 shows the 21 prospective teachers submitted a total of 89 web pages, 59 background images, 80 graphic images, 85 in-site links, and 28 WWW links in the sections of the website they completed. The number of web pages prepared by the pre-service teachers ranged from 3 to 8 and the median number of pages prepared was 3 . The number of images (both background and graphics) used by the future teachers in completing the website project ranged from 3 to 11 with a median number of 7 . Also, the number of links (both in-site and WWW) created by the prospective teachers ranged from 2 to 14 with 7 being the median number.

Table 1. Online elements submitted in Completion of Website Project

\begin{tabular}{ll}
\hline Element & Number \\
\hline Web Pages & 89 \\
Backgrounds & 59 \\
Images & 80 \\
In-site Links & 85 \\
WWW Links & 28 \\
\hline
\end{tabular}

A count of images and links showed the future teachers completed an average number of 2.8 background images, 3.8 graphics images, 4.0 in-site links, and 1.3 WWW links in the web pages they created. In particular, the number of background images that were used ranged from 0 to 4 with a median number of 3 . The number of graphics images used ranged from 2 to 7 with 4 being the median; the number of in-site links ranged from 0 to 11 with a median of 3 ; and the number of WWW links used varied between 0 and 3 with a median number of 1 . Figure 1 shows that the average number of web pages, images, and links used by the pre-service teachers in completing the project was $4.2,6.6$, and 5.4 , respectively.

A total of 22 of the pre-service teachers completed the five items on the course final exam related to the creation and modification of web pages. The overall average score of the future elementary school teachers on these items was $73.6 \%$ while the overall average score on the future teachers on all items on the final exam was $68.7 \%$. The most difficult of the final exam items that dealt with web pages was an item about the types of files that produce illustrations on a web page. Twelve of the 22 pre-service teachers correctly answered this item, while all except one of the future teachers correctly answered the easiest item, an item concerning the mode to use when inserting background images into web pages. 


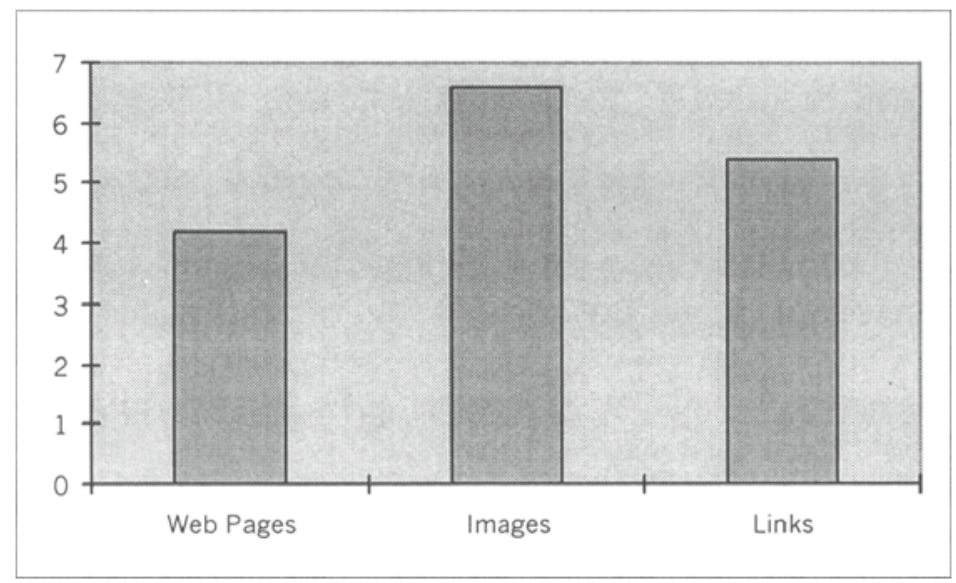

Figure 1. Average Number of Web Pages, Images, and Links Submitted

Nineteen of the 22 pre-service teachers took the final exam together and these students were asked to complete the questionnaire about the website project. A total of 17 completed questionnaires were received from these 19 prospective teachers.

In response to the first questions on the questionnaire: 'Did you like the website project? Why or why not?', a majority ( $71 \%$ or 12$)$ of the students indicated they enjoyed the project. As reasons given for enjoying the project, the students indicated they enjoyed looking at their work on the web or surfing the Internet to view educational sites, or learning about making web pages or computers. Among those students who wrote that they did not like the project, the predominant reason given concerned a lack of time to work on the project. Other negative comments related to hardware problems, the difficulty of the project, lack of help by computer lab staff, and the need for more information on the website editor or web research.

The second item on the questionnaire was 'What did you learn from doing the website project?'. Most the responses (12 of 17) related to the use of the web editor software or to creating and uploading of websites. A few students also wrote that they learned about teaching ideas or about how much time was required to build websites.

Item 3 on the questionnaire, "Why did you select the material you included in the web pages on the mean, median, and interquartile range?', generated replies that mainly focused on the desire for simplicity, clarity, pertinence, a high level of interest, and attractiveness. Several students also reported that the material they used was the best they could find given the time constraint.

The last item on the questionnaire asked the future teachers to describe the ways they might use websites in the classroom. Most of the prospective 
teachers described one of three uses: as a source of information for or about classroom assignments, as a source for online help with homework, or as a source of games that help in learning mathematics. The remaining respondents related that they might use websites in the classroom to enable parent-teacher or teacher-student communication, or to teach topics related to the use of technology, or to present enrichment, review/re-teach topics, or deliver instruction by means of a 'different and fun activity'.

Students' use of their websites' internal discussion forum was also investigated. Initially, the discussion forum was set up as a means for students to inform one another of helpful or interesting websites. This objective was met when students posted the URLs of mathematical websites or pertinent graphics for their projects. However, the forum rapidly evolved into a networking tool when students began to post questions, provide advice, and suggest other directions for the projects. Students were encouraged to interact on the forum, and many students later remarked on the value and usefulness of the discussion forum and on its ease of use. As a result, it often appeared that the forum allowed students to explore a variety of valuable and interesting Internet sources and to compile a list of these resources for future use. Perhaps more importantly though, the forum engaged students in discussions about the quality and mathematical content of websites, and these discussions allowed students to gain insight into both teaching approaches and current technology.

For example, one forum discussion revolved around the discovery and sharing of a statistical website. Several students first wrote about their excitement in locating the site, but as the discussion progressed, two students questioned the quality and computations within the site. One student indicated that without this shared experience, she would have been impressed with the surface features of the site, but unaware of the shortcomings and errors within the site.

\section{CONCLUSION}

Based on the overall average score of $87.3 \%$ earned by these pre-service teachers on the website project and the overall average score of $73.6 \%$ they earned on website items on the final exam, there is good evidence that website construction can be an appropriate and reasonable part of the mathematics curriculum for prospective elementary school teachers. The preliminary task of uploading partially completed websites for each of the pre-service teachers to modify and upload required a substantial amount of preparation time and three, busy, 110-minute class sessions. Having a teaching assistant to help the instructor with both the preparation and the hands-on computer sessions would be a tremendous asset in facilitating 
future small classes, and such assistance would probably be an absolute necessity for larger classes or even multiple small classes.

Student performance on particular website projects showed that the completed sites contained, on the average, approximately 4 new web pages, 7 graphics, and 5 links. This data again provides evidence that the project was an appropriate and reasonable undertaking for these future teachers, since the assignment simply asked that they replace the 3 given pages with web page(s) and that they create their own graphics, text, and links within these pages. About $42 \%$ of the graphics in the completed websites were used as background images and about $25 \%$ of the links in the completed websites were links to pages outside the website. These figures likely reflect the technically more difficult natures of (1) making background images for web pages, as opposed to inserting a graphics image in a web page, and (2) making a link to the WWW, as opposed to making a link to a page with the same website.

Some completed websites appeared to make better use of images in creating a unified appearance for those pages that reviewed a particular topic. For instance, one prospective teacher's site contained the same background image for each page along with a small graphic of a fractal. Using such a consistent design scheme appeared to unify the entire site and imbue a sense of dependability, predictability, and reassurance to the content as was earlier observed by Shotsberger (1996). Future projects involving the construction of instructional websites in mathematics may wish to emphasise this design consideration.

More than $70 \%$ of the future teachers indicated that they liked the website project in responding to the post-project questionnaire, and the majority of those who indicated they did not like the project cited time limitations as the reason. The fact that the project was due on the last day of classes for the term may have contributed to the time pressures that were referenced by both those who liked and disliked the project. Other negative comments related to hardware problems or the lack of available help while at the computer. Some hardware problems appeared to be defective machines, but others were likely caused by overloading communication links to the computers hosting the student accounts. For example, in demonstrating how to upload a website there was no success when all students attempted to upload almost simultaneously, but all students were able to upload their sites when this task was later completed individually. Knowing in advance these and similar hardware pitfalls should provide future instructors with instructional time to give more attention to online help features thereby alleviating some concerns about the availability of help at the computer. 
More than $70 \%$ of the pre-service teachers also indicated on the questionnaires that they learned technical skills related to web, but few of the respondents indicated they had learned about mathematics. In retrospect, it appears that a greater emphasis on the mathematical content of the project can be achieved by providing more details about the mathematics to be put on the web pages. This type of revised assignment could, for example, specify that the review of the median should include both grouped and ungrouped data, both odd and even amounts of data, and exercises that involve conceptual understanding as well as problem solving rather that simple computational skills.

Analysis of the last two questionnaire items revealed that these prospective teachers foresaw their future classroom websites to be primarily sources of information, albeit information that is understandable, clear, pertinent, and attractively and interestingly presented. A few respondents did express expectations of using websites more as a interactive tool, either as a helper with homework or as a generator of spreadsheet-based mathematical games. These responses may have been due to the fact that immediately prior to the website project the pre-service teachers completed a unit on using spreadsheets in mathematics. Greater integration of the content on spreadsheets and websites in courses for prospective elementary school mathematics teachers is apt to further enhance awareness of the potential of the web for instructional interaction.

The present study also provided the future teachers with several examples of links to WWW sites that illustrated the conferencing potential of the web (Foley and Schuck 1998). In the tally of the links submitted by the future teachers in their completed website projects, approximately $25 \%$ of these links were to web locations that functioned, at least partly, as conferencing or interactive sites. As a result, it appears likely that these future teachers will come to rely, perhaps more than they anticipated or verbalised in this study, on learning approaches that are enhanced by webmediated interaction.

\section{REFERENCES}

Charland, T. S. (1998) Classroom homepage connections. Technological Horizons in Education April 1998, 62-4.

Foley, G. and Schuck, S. (1998) Exploring the potential of a web-based conferencing tool in mathematics education. Proceedings of the International Commission on Mathematical Instruction - First East Asia Regional Conference on Mathematics Education 3, 167-179. Korean Society of Mathematical Education, Seoul.

Gerber, S., Shuell, T. J., and Harlos, C. A. (1998) Using the Internet to learn mathematics. Journal of Computers in Mathematics and Science Teaching 17(2/3) 113-132. 
Halpin, P. and Kossegi, J. D. (1996). The WWW, pre-service teachers and their mathematics courses. Paper presented at the Summer Conference of the Association of Small Computer Users in Education, June 1996. North Myrtle Beach, South Carolina.

Jiang, Z. and McClintock, E. (1997). The World Wide Web - A powerful learning tool for preservice mathematics teachers. Paper presented at the National Conference on College Teaching and Learning, April 1997, Jacksonville, Florida.

Shotsberger, P. G. (1996). Instructional uses of the World Wide Web: Exemplars and precautions. Educational Technology March/April 1996, 47-50.

\section{BIOGRAPHIES}

Jack Carter received his doctorate in mathematics education from the University of Texas at Austin. Since 1981 he has taught in the Department of Mathematics and Computer Science at California State University, Hayward. His research interests include teaching and learning undergraduate mathematics, comparisons of national systems of mathematics education, and the use of technology in mathematics instruction.

Beverly J. Ferrucci is Professor of Mathematics at Keene State College in Keene, New Hampshire. She received a doctorate in mathematics education from Boston University and a doctorate in psychometrics from Boston College. She is the editor of the New England Mathematics Journal, and her research interests include pre-service and in-service education of teachers in mathematics, technology and cross-cultural studies of prospective mathematics teachers. 